\title{
INFORMATION SYSTEMS ANALYSIS AND DESIGN COURSE FOR COMPUTER ENGINEERING
}

\author{
Ricardo Chalmeta ${ }^{1}$, Manuel Mollar ${ }^{1}$, Salvador Sanchez ${ }^{2}$ \\ ${ }^{1}$ Grupo de Integración y Re-Ingenieria de Sistemas, Universitat Jaume I (SPAIN) \\ ${ }^{2}$ Pattern Analysis and Learning (PAL), Universitat Jaume I (SPAIN)
}

\begin{abstract}
Computer engineering is a branch of engineering that integrates several fields of computer science and electronics engineering required to develop computer hardware and software. The Universitat Jaume I (UJI) of Castellón, Spain, is teaching the Bachelor's Degree of Computer Engineering. The degree's aim is to train students with the abilities to design, implement and maintain computer systems for any sector of economic activity. These studies were in the past a five years preBologna curriculum and now they are developed under the Bologna approach. Four professional profiles are established for graduates in this degree: Specialization track in information technologies, Specialization Track in Computer Engineering, Specialization Track in Information Systems and Specialization Track in Software Engineering.

The degree is composed by different courses. One of these courses is the information systems analysis and design course. It addresses the necessary basic knowledge and competencies to produce graduate with the advanced knowledge, skills, expertise and competencies required to apply a systematic methodology for the analysis and design of information systems, together with the appropriate methods, techniques and tools.

The aim of this paper is to show the methodology and learning solutions used to train the students to undertake information systems analysis and design in any kind of organizations. Paper shows the course objectives, the target competencies, the course contents, the assessments, and how the technology resources for e-learning are used to teach the subject.
\end{abstract}

Keywords: Information Systems, Analysis and Design, Methodology and learning solutions, Computer Engineering, Curriculum Design.

\section{INTRODUCION}

Information system analysis and design deal with planning the development of information systems through understanding and specifying in detail what a system should do and how the components of the system should be implemented and work together. System analysts solve business problems through analyzing the requirements of information systems and designing such systems by applying analysis and design techniques [1].

This paper describes the information systems analysis and design course course of the Bachelor's Degree of Computer Engineering at the Universitat Jaume I (UJI) of Castellón, Spain. The focus of this course is on studies of specifications of the information systems development process. The course covers fundamental topics on two main stages of information systems development life cycle: analysis, and design. Students will become familiar in techniques to investigate, collect, organize, and structure requirements for an information system as well as understanding how to design different component of the information system to satisfy the requirements. The course hands-on experiences such as working directly with real-world clients to address an information need challenge. Paper shows the course target competencies, the course contents, the assessments, and how the teaching methodology and the resources are used to teach the subject.

\section{OBJECTIVES}

The main objectives are to provide the student with knowledge about methodologies, techniques, and tools for the analysis and development of information systems. The subject will focus on the phases of specification and requirements engineering, and the UML technique [2, 3]. 


\section{LEARNING OUTCOMES/CAPABILITY DEVELOPMENT}

\subsection{Specific capabilities}

- Utilize conceptual frameworks to align IT investments with business strategy

- Specify business requirements as information system specifications

- Assess the fit between business requirements and enterprise systems features

- Evaluate technological alternatives for developing the IT infrastructure for the organization

\subsection{Cognitive Capabilities}

- Computer literacy

- Analytic/design (conduct research, analyze, reason, solve problems, interpret data)

- Appreciative (evaluate ideas, make judgements, think critically, multidisciplinary perspectives, self-recognition)

\subsection{Behavioural Capabilities}

- Personal (think and act independently, creativity, tolerant of ambiguity, flexible)

- Interpersonal (listening, presentation, communicate, negotiate, group dynamics, collaboration)

\section{LEARNING METHODOLOGY}

A methodology based on continuous evaluation is used, together with the encouraging of the students' autonomy and promotion of the cooperative work. So, the final objective is to learn to learn.

In order to promote the autonomy of the students, they have to prepare several readings and exercises before the sessions of theory. These sessions present practical activities on the subjects prepared before by the students and the teachers explain the main contents of theory and solve any doubts that may arise. The objectives of the theory can be organised in five areas:

Information Systems in the Company. The goals of this section are: Present the fundamental processes of the companies and the associated information flow; and understand that a computer system is not an isolated object and that it influences the functioning of the environment where it is implemented, both in the management and in the people who use it.

Fundamentals of Information Systems. The goals of this section are: To know the concept of the system and the different types of information systems, as well as the fundamental elements or components that must be considered for the correct development of them.

Information Systems Planning. The goals of this section are: Learn to identify possible problems in the organization related to the computerization of the same; Show basic concepts about the software, its evolution, applications, etc.; Present different techniques that can be used for the analysis of requirements and the analysis and design of software, data and user interfaces; Present a methodology for the development and implementation of computer systems; Show a method for the evaluation and selection of software; Present the student with a series of commercial computer tools to help decision-making in the integrated management of the company and production (ERP's).

System Analysis. The goals of this section are: Learn to model a computerized system based on the previously developed requirements definition; Understand the need to represent the structure of information and its relationships to complete the analysis; Know how to develop a conceptual data model and refine it by applying some of the normalization rules; Evaluate possible alternatives of representation of the model to study in a reasoned manner which is better suited to the system to be developed; Learn to document a model properly.

Design of Systems. The goals of this section are: To know the activities of the design stage and the importance of an adequate development for the correct implementation of the system; Understand the need to develop user interfaces appropriate to the capabilities and the use that each user must make; Learn to design screens and reports appropriate to user profiles and system characteristics. 
On the other hand, in the practices, students work in groups of 5 people using the technique of case study with the purpose of carrying out a project of software requirements definition, analysis, and design to support a business process in a company or public administration. In the practices different information systems modeling tools are used to carry out the project.

The case study is broken down into the following phases, according to the methodology explained in the theoretical sessions:

1 Analysis of the company

\subsection{Overview}

\subsubsection{Mission and vision}

1.1.2. Strategy and Strategic Objectives

1.1.3. Products / services

1.1.4. Technological, human, organizational and economic policies

1.2. Business processes

1.2.1. Process map.

1.3. Technological level

1.3.1. Systems and Information Technology

1.3.2. Other technologies

2 Selection of a domain

2.1. Textual description of the current situation

2.2. Model IDEF0

3 Application of the systematic approach to the Re-engineering of the process

3.1. Problem definition

3.2. Developing alternatives to improve the business process based on information systems

3.3. Selection. Justify feasibility

3.4. IDEF0 model of the new process

4 Analysis and Design of the Information System

4.1. BPM model

4.2 User interface (optional)

5 Temporary and economic costs

6 Bibliography

\section{SYLLABUS/COURSE CONTENT}

The course contents are:

TOPIC 1: INTRODUCTION. SOFTWARE ENGINEERING AND INFORMATION SYSTEMS

1 Introduction: What is an information system?

2 Types of Information systems

3 Components of an information system

4 Software Engineering Paradigms

TOPIC 2: DEFINITION OF REQUIREMENTS.

1 Objectives

2 Preliminary research

3 Requirements Definition Techniques

3.1. Revision of the current system 
3.2. Interviews and questionnaires

3.3. Analysis of functional areas

3.4. Prototypes

4 Classification and documentation of requirements

TOPIC 3: MODELING AND ANALYSIS.

1 UML Data Modeling

2 Process modeling with UML

TOPIC 4: SYSTEMS DESIGN.

1 Introduction

2 Design of user Interfaces

2.1. Types and Conditions.

2.2. Screen Design

2.3. Design of reports.

3 Design of processes and tools

3.1. Structure diagram

3.2. Design Quality

4 Planning of installation, conversion and start-up.

\section{ASSESSMENT}

Continuous Evaluation 60\%

Exam $40 \%$

\section{CONCLUSIONS}

This paper shows the curriculum design of information systems analysis and design course. This curriculum has been developed by teachers of computer systems department at Universitat Jaume I. The results of the course is that students improve their knowledge and capacities in four specific information systems domains: System development project planning (with focus on preparing a proposal and feasibility analysis); Requirements specification (with focus on information gathering and building process \& entity models); Design specification (with focus on system architecture, Input/Output design, database schema and structure chart); and Implementation (with focus on creating user interfaces and prototypes, documentation - user and system).

The approach used in teaching this course, with both business and technical backgrounds, enhances students' learning and simulates what these students will encounter when they join the workplace. The project-driven approach used in this course offers additional learning opportunities. Students learn about business value of the IS solution, and they appreciate the challenges of implementing an information system solution. This method allowed students to work in teams and helped them develop interpersonal and communication skills. The students also developed trust and respect for both disciplines represented in the course.

Although some students were initially concerned about the practical approach used in the course, they quickly realized the value of such approach, that prepares them for challenges and opportunities that they are bound to encounter in the real-world. The result is that students are very satisfied with course contents and organization. The focus in practical work makes than theory can be understood easier, and students obtain new knowledge and new skills, similar to professional work.

\section{REFERENCES}

\section{Basic bibliography}

[1] C. Larman. Applying UML and Patterns (3rd edition). Prentice Hall, 2005. 
[2] Klaus Pohl. Requirements Engineering: Fundamentals, Principles, and Techniques. Springer Publishing Company, Incorporated, 1st edition, 2010.

[3] R.S. Pressman. Software Engineering. A Practitioner's Approach (7th edition). Mc Graw-Hill, 2005.

\section{Additional bibliography}

[4] S.W. Ambler. The Elements of UML 2.0 Style. Cambridge University Press, 2005.

[5] G. Booch, J. Rumbaugh, and I. Jacobson. The Unified Modeling Language User Guide, Second Edition. Addison Wesley, 2006.

[6] A. Cockburn. Writing Eective Use Cases. Addison Wesley, 2006.

[7] M. Fowler. UML Distilled: A Brief Guide to the Standard Object Modeling Language. AddisonWesley, 2003.

[8] I. Jacobson, G. Booch, and J. Rumbaugh. The Unified Software Development Process. Addison-Wesley, 1999.

[9] OMG. Unified Modeling Language. Object Management Group, version 2.5.1 edition, December 2017.

[10] OMG. Object Management Group. http://www.omg.org/, 2018.

[11] M.G. Piattini, J.A. Calvo-Manzano, J. Cervera, and L. Fernandez. Análisis y diseño detallado de Aplicaciones Informáticas de Gestión. Ra-Ma, 2004.

[12] P. Roques. Les Cahiers du programmeur UML2. Modeliser une application web (4e edition). Eyrolles, 2002.

[13] P. Roques and F. Vallee. UML 2 en action. Eyrolles, 2004.

[14] J. Rumbaugh, I. Jacobson, and G. Booch. The Unied Modeling Language Reference Manual, Second Edition. Addison Wesley, 2006.

[15] I. Sommerville. Ingeniera del software (7a Edicion). Pearson Addison Wesley, 2005.

\section{Websites}

[16] Use Cases: http://alistair.cockburn.us/Use+cases

[17] OMG: http://www.omg.org/

[18] UML: http://www.uml.org/

[19] UML Tool IBM Rational software: http://www.ibm.com/Rational

[20] UML Tool MagicDraw: https://www.nomagic.com/products/magicdraw 